This is of interest in the study of cosmic development.

Poughkeepsie, N.Y., June 16, 1883. C. B. WARRING.

\section{Flight of the flying-fish.}

The difficulties in the way of accurate observation of the flying-fish in motion are numerous and real. Seen always from above, usually at a distance which is constantly increasing, and while the observer himself is in rapid motion, it is not strange that such conflicting opinions exist, or that the mode of flight is so often spoken of as a mystery.

During a trip by steamer from New York to Rio Janeiro viâ the West Indies and Pará, and on the return trip coming directly from Rio to New York, I watched flying-fish nearly every day, and frequently all day, and satisfied myself on the following points :-

The fish usually leaps clear of the water at once, leaving it commonly at an angle of $45^{\circ}$ or less. After leaving the water, no forward impulse whatever is received (except sometimes from the wind) until the water is again touched, when the tail may be used effectively without immersion of the rest of the body. Very soon after leaving the water, yet not instantly, the pectorals are spread, and an instant later the ventrals.

Both sets of fins are kept quietly extended so far as any voluntary vibration is concerned. Any similar, tensely stretched membrane would quiver more or less when cutting the air at such speed.

Ordinarily the two pectorals lie in about the same plane. They are never carried much below the body, but are frequently lifted considerably above it, especially when going before the wind, at which time the whole fish rolls from side to side, precisely as does a sailing-vessel under similar circumstances. The course may be a simple curve, as it commonly is in calm weather, or it may be undulating, as is usually the case in rough weather or over a heavy swell. I think the ventrals are used to direct the fish up or down, as they certainly work independently of the pectorals, and closing them would naturally drop the tail. Toward the close of the first stretch, and when the fish wishes to re-enter the water, the pectorals are instantly closed, and he shoots head foremost into the water with only a slight splash.

If, on the contrary, he wishes to continue in the air, the long lower lobe of the tail is allowed to drop into the water, and a few vigorous strokes send him upward and forward, sometimes enabling him to clear another hundred feet before repeating the action, which I have seen him do at least seven or eight times before finally entering the water for a fresh start.

Not unfrequently the tail is dropped, seemingly by closing the ventrals, and an undulating motion so obtained, even when there are no waves or swells to be cleared; and, although the tail may not then touch the surface, it looks as if the fish were feeling for the water, which I think is really the case. The poetic wetting of the wings in the crest of a wave so as to prolong the flight appears to be a harmless bit of imagination for all but the fish: to him it is disastrous. His tail alone needs wetting; and, when by mistake he takes the top of a wave bodily, it usually topples him over, or at least checks him noticeably. The drying of the wings would be rather favorable than otherwise.

I was not able to detect any voluntary change of direction to right or left while in the air.

Once a large fish rose quite close to us, and started directly toward the steamer. When within a few yards, he suddenly closed his pectorals, plunged into the water, and almost instantly issued again in a nearly opposite direction.

Examination of a Pacific species in alcohol (and I presume the same general structure holds good for the genus) shows that the pectorals are inserted at such an angle with the axis of the body, that, if the body be horizontal and in motion, the air striking on their lower surfaces must tend to raise the fish, although at the expense of a certain amount of forward motion. Evidently, then, any beating of the pectorals would only retard the fish still more, even if it did support him somewhat in the air. The conclusion seems inevitable, however, that the tail alone is the propeller, the other fins acting solely and passively as supporters. WALTER B. BARROWs.

Wesleyan university, Middletown, Conn.

\section{HEITZMANN'S MICROSCOPICAL MORPHOLOGY.}

Microscopical morphology of the animal body in health and disease. By C. Hertzmann, M.D. New York, J. H. Vail \& Co., 1883. $19+849$ p. $8^{\circ}$.

Dr. Heitzmans, formerly of Vienna, now of New York, is well known as an unusually good histological draughtsman. Ten years ago he published some investigations on the minute structure of protoplasm. To his own researches on this subject he has long attributed an importance which scientific men of much greater experience and ability have failed to recognize. The present volume, a very well made and beautifully illustrated book, although it comes in the guise of a manual of normal and pathological histology, is obviously intended principally to bring forward the author's own theories, and to insist upon their fundamental character and great value.

The author so openly implies his conviction that he is a neglected grandeur, that he incites the critic to a severity of comment that a tone of modesty more commensurate with the real value of his researches would not have called - forth. The general defect of the book is want of judgment on the author's part, and an exaggerated confidence in his own notions. Thus, being unusually skilful with his fingers, he scoffs at microtomes (p. 7), and closes a slurring paragraph upon them with, "The greater the complication, the less is the value of such machines." A man who makes such a statement without any limitation reveals a hopeless lack of comprehension of the indispensable requirements of many branches of histological investigation. 'The second chapter in the book discusses the general properties of living matter, and contains a number of characteristic loose assertions: for instance, "Life is evidently a peculiar kind of motion of the molecules (plastidules) of living matter, of a relatively short duration" (p. 14). This is 